\title{
A Escola Galesa de Estudos Críticos em Segurança Internacional: 25 anos depois ${ }^{1}$ \\ The Welsh School of Critical Security Studies: 25 years after
}

DOI: $10.21530 /$ ci.v12n1.2017.609

Aureo de Toledo Gomes²

\section{Resumo}

Tendo como fio condutor os trabalhos de Ken Booth e Richard Wyn Jones, o artigo analisa a produção acadêmica da Escola Galesa de Estudos Críticos em Segurança Internacional. O argumento a ser desenvolvido é que, a despeito da produção de conceitos que contribuíram para o campo crítico em Segurança Internacional, o desenvolvimento teórico da escola ainda padece de insuficiências, sobretudo a controversa relação entre segurança e emancipação. Por conseguinte, derivar conceitos que informam a ação política torna-se tarefa difícil. Logo, a análise aponta para a necessidade de a Escola Galesa engajar-se em um debate teórico com perspectivas distintas, especialmente o pós-estruturalismo e o pós-colonialismo, o que pode produzir implicações importantes para a teoria e prática dos Estudos Críticos em Segurança Internacional.

Palavras-chave: Escola Galesa; Segurança Internacional; Emancipação.

\begin{abstract}
Anchored in the works of Ken Booth and Richard Wyn Jones, the article reviews the academic production of the Welsh School of Critical Security Studies. It is argued that despite a meaningful conceptual contribution to critical security studies, the Welsh School production is still pervaded by weaknesses, mainly the troubled security and emancipation equation. Thus, deriving concepts for political action becomes an arduous task. The analysis points

1 Gostaria de agradecer a Rafael Villa e Thiago Babo pelo convite para escrever sobre a Escola Galesa de Estudos Críticos em Segurança Internacional no âmbito de projeto desenvolvido junto ao NUPRI-USP. Ademais, agradeço novamente a Thiago Babo pelos comentários a uma versão prévia do trabalho durante o I Encontro Brasileiro de Estudos para Paz, em setembro de 2016. Não menos importante, o meu muito obrigado também se estende aos pareceristas anônimos da revista Carta Internacional.

2 Professor Adjunto III do Instituto de Economia e Relações Internacionais da Universidade Federal de Uberlândia. E-mail: aureotoledo@ufu.br

Artigo submetido em 10/01/2017 e aprovado em 05/04/2017.
\end{abstract}


towards the need for a thorough engagement with other theoretical lineages such as poststructuralism and post-colonialism. This dialogue might produce significant consequences for the theory and practice of critical security studies.

Keywords: Welsh School; Security Studies; Emancipation.

\section{Introdução}

Passado mais de um quarto de século desde a publicação do seminal ensaio Security and Emancipation, de Ken Booth (1991a), não restam dúvidas sobre o impacto do que se convencionou chamar Escola Galesa de Estudos Críticos em Segurança Internacional ${ }^{3}$. Conforme recente balanço, adeptos das ideias produzidas por tal corpo teórico contribuíram para a elaboração de análises sobre segurança não apenas a respeito do Ocidente, como também em relação a África, Ásia e outras regiões. Ademais, cursos de pós-graduação passaram a ser oferecidos em diversas universidades, assim como periódicos especializados ocupam cada vez mais espaço acadêmico (BILGIN, 2011). Em suma, a Escola Galesa estaria caminhando de forma sustentável ${ }^{4}$.

Todavia, tal diagnóstico otimista não é consensual, sobretudo quando o que se está sob escrutínio é o potencial heurístico desse corpo de ideias. Dentre as principais críticas, argumenta-se que a Escola Galesa carece de uma apreciação mais refinada sobre a ética da segurança e de como tais debates informam a natureza e dinâmica de um possível progresso social (BROWNING; MCDONALD, 2011). Ademais, há aqueles que argumentam em prol da retirada do termo Crítico, com base no fato de que o impulso emancipatório dos anos 1990 perdeu-se nos trabalhos mais recentes, substituído agora por horizontes progressistas mais modestos. O argumento é que, sim, devemos estudar segurança internacional, seus discursos e práticas, porém estudo não é sinônimo de crítica (HYNEK; CHANDLER, 2013).

Frente a tamanha controvérsia, o objetivo do trabalho é analisar o desenvolvimento da Escola Galesa de Estudos Críticos em Segurança Internacional.

3 Quando em caixa alta, Segurança Internacional refere-se ao subcampo de conhecimento das Relações Internacionais, enquanto segurança internacional refere-se ao objeto de estudo desse subcampo.

4 O primeiro curso em nível de pós-graduação sobre Critical Security Studies foi ministrado durante os anos de 1995 e 1996, conduzido por Booth, Wyn Jones e Nicholas Wheeler e com um público inicial de 5 alunas e alunos a partir do departamento de Política Internacional da Aberystwyth University, no País de Gales (Bilgin, 2011). Desde então, novos centros foram formados, particularmente no Reino Unido, Austrália e Turquia, aonde estão lotados egressos como Adam David Morton e Pinar Bilgin. Outrossim, a Escola Galesa passou a fazer parte do currículo escolar sobre segurança internacional em cursos de graduação e pós-graduação. 
Metodologicamente, o artigo realiza uma revisão da literatura, tendo como fio condutor obras de Ken Booth e Richard Wyn Jones, e a ela adiciona críticas contemporâneas ao trabalho da Escola, porém não se esquivando de, ao final, a partir de tal arrazoado, lançar suas próprias interrogações. A proposta se justifica, pois, para além da relevância da discussão, no Brasil, com exceção de Azevedo (2009), são raros os trabalhos que se propõem a aplicar ou mesmo realizar balanços sobre essa linhagem teórica.

O texto divide-se em quatro partes, excetuando-se esta introdução. A primeira seção apresenta os principais desenvolvimentos teóricos da escola, com ênfase na problematização ao conceito de segurança. Em seguida, ilustra-se a operacionalização dessa abordagem mediante trabalhos empíricos que fazem uso desse conjunto de ideias. A terceira seção discute críticas recentes à produção teórico-empírica da Escola Galesa. A última seção prospecta potenciais respostas às críticas levantadas.

\section{Teoria}

É praticamente lugar-comum destacar o impacto que o final da Guerra Fria teve sobre a área de Relações Internacionais ${ }^{5}$, e sobre o subcampo da Segurança Internacional em particular. Academicamente, os efeitos sistêmicos de tamanha transformação permitiram o fortalecimento de correntes críticas que, desde o começo dos anos de 1980, já questionavam a primazia neorrealista (GEORGE, 1994). Politicamente, o fim da bipolaridade reduziu a importância da competição estratégico-militar entre EUA e URSS para a compreensão da política internacional, abrindo espaço para que temas considerados marginais na agenda passassem a ocupar espaço (BUZAN; HANSEN, 2012).

A conjunção de ambos desenvolvimentos criou as condições para questionamentos sobre a natureza do conceito realista de segurança. Tomando Stephen Walt (1991) como referência dessa linhagem, os estudos de segurança teriam como propósito buscar conhecimento cumulativo sobre a ameaça, uso e controle da força militar. Todavia, quando confrontada com o cenário supracitado, tal definição parecia, ao menos para teóricos críticos, insuficiente por uma série de motivos, dos quais dois merecem maior apreciação.

5 Relações Internacionais em maiúsculas faz referência à área do conhecimento. Em caixa baixa, relações internacionais refere-se a seu objeto de estudo. 
O primeiro motivo seria uma insuficiência relativa ao objeto da segurança. Centrar a discussão no campo militar e estatal parecia restringir por demasiado a dimensão das ameaças contemporâneas. Tal viés estadocêntrico é, a um só tempo, um posicionamento normativo, pois trata o Estado como referente último e agente de segurança, para quem todos os cidadãos devem lealdade e onde o poder decisório está concentrado, assim como é uma opção metodológica, visto que envolve restringir as dinâmicas internacionais a partir de uma perspectiva cujo centro é o Estado. O segundo motivo seria as ancoragens ontológica e epistemológica dos estudos de segurança. O conhecimento cumulativo que Walt faz referência em sua definição é reflexo de uma concepção positivista de ciência, no qual o objetivo é a busca por leis causais que informariam o comportamento humano. As implicações de tal posicionamento estão longe de serem incontroversas. Ontologicamente, assume-se uma determinada concepção de subjetividade humana, entendida a partir da imagem de seres racionais que fazem uso instrumental da razão vis-à-vis uma realidade externa com a qual se relacionam de forma objetiva. Epistemologicamente, pressupõe-se uma separação entre sujeito cognoscente e objeto, assim como procura-se separar fatos de valores (KRAUSE; WILLIAMS, 1997).

Logo, uma série de analistas interrogou criticamente a natureza do conceito de segurança. Um importante ponto de confluência desses debates à época foi a conferência organizada pelo Center for International and Strategic Studies na York University, em Toronto, Canadá, entre 12 a 14 de maio de 1994. A partir dos debates suscitados, cunhou-se o termo critical security studies para abarcar os projetos intelectuais cuja meta era questionar o conceito de segurança. O principal produto desse evento foi a publicação, em 1997, do volume organizado por Keith Krause e Michael C. Williams, Critical Security Studies: Concepts and Cases.

Todavia, parece-nos razoável entender o prefixo crítico nesse momento em sentido lato. A conferência e o livro serviram como trampolim para fomentar estudos críticos em Segurança Internacional, porém não os preencheram com um conteúdo preciso (MUTIMER, 2007). Abriram-se então as portas para que contribuições marxistas, feministas, pós-estruturalistas, dentre outras, passassem a confrontar a tradição realista de segurança. A despeito de suas diferenças, todas essas abordagens compartilham reflexões sobre o conceito de segurança, sobretudo quem ou o que deve ser assegurado, assim como uma visão de segurança e de seus conceitos enquanto prática que não apenas descreve a realidade, mas também a constrói ao ser reiterada constantemente. 
Em sentido estrito, o termo Crítico - agora em caixa alta - foi imputado a um grupo específico de analistas, pois procuravam trazer para o subcampo da Segurança Internacional insights da Escola de Frankfurt, dos Estudos para Paz e de Antonio Gramsci, provavelmente incentivados pela contribuição seminal de Robert Cox (1981), o qual abriu a área de Relações Internacionais para o que se convencionou chamar de abordagens neogramscianas. Esse conjunto de autores e autoras ficou conhecido como Escola Galesa de Estudos Críticos em Segurança Internacional, capitaneada pelos trabalhos de Ken Booth e Richard Wyn Jones ${ }^{7}$.

Convém, contudo, recordarmos alguns pontos. Ao menos desde finais da década de 1970, Booth já vinha questionando os fundamentos dos estudos estratégicos ${ }^{8}$. Já em 1991, o mesmo autor havia publicado dois textos importantes - Security in Anarchy: Utopian Realism in Theory and Practice (BOOTH, 1991b) e o já citado Security and Emancipation - considerados marcos da Escola Galesa. Logo, percebe-se que não se tratam de trabalhos iniciados a partir da conferência de 1994, mas sim que a antecedem e que certamente foram potencializados pela conjuntura pós-Guerra Fria.

Que contribuições a Escola Galesa aportou às discussões sobre segurança internacional? Conforme dito, um de seus extratos conceituais é a tradição da Teoria Crítica frankfurtiana. Em linhas gerais, tal corrente tem a meta de compreender situações sociais de desigualdade, opressão e injustiça não apenas com o intuito de produzir análises, mas também identificar possibilidades concretas de superação dos problemas. O diagnóstico realizado deve apontar ao mesmo tempo tanto para as patologias quanto para os potenciais práticos de transformação. Como sintetiza Nobre (2004, p. 10), o ponto de vista crítico é aquele que vê o que existe a partir da perspectiva do novo que ainda não nasceu, mas que se insinua no presente.

6 Estudos para Paz (Peace Studies) fazem referência aos esforços de analistas que, a partir da década de 1960, passaram a incentivar discussões sobre paz. Destaca-se a produção de Johan Galtung (1969), particularmente sua distinção entre paz negativa, entendida enquanto ausência de conflito, e paz positiva, que deveria atentar também para aspectos estruturais que impediam a concretização de uma situação de paz.

7 Vale salientar que a Escola Galesa não é a única escola crítica em Segurança Internacional. Conforme Waever (2004), há ao menos duas outras importantes tradições. De um lado, temos a Escola de Copenhague liderada por Barry Buzan e Ole Waever e cuja principal contribuição para o campo é a teoria da securitização. Grosso modo, securitização seria uma prática performativa mediante a qual o ator securitizador identifica uma ameaça existencial a um objeto referencial, o que justificaria a adoção de medidas excepcionais. Ademais, temos ainda a contribuição da Escola de Paris, exemplificada pelos trabalhos de Didier Bigo e Jef Huysman, os quais, dentre outros pontos, destacam como os domínios doméstico e internacional de segurança se fundiram nos últimos anos e quais as implicações analíticas e políticas desse processo.

8 A referência aqui é o livro de Booth de 1979, Strategy and Ethnocentrism. 
O link entre essas ideias e o subcampo da Segurança Internacional jaz já no título do seminal artigo de Booth, de 1991, e posteriormente em seu livro de 2007, assim como em trabalhos de Wyn Jones (1995; 1999; 2005): segurança seria, teoricamente, emancipação. Destrinchando o argumento, partamos da definição padrão que Booth (1991a; 2005b; 2007) utiliza: segurança seria basicamente a ausência de ameaças. Quando mergulhamos nas nuances dessa afirmação, 3 pontos saltam aos olhos: a existência de um referente da segurança; um perigo, real ou provável; e o desejo de escapar das possibilidades ameaçadoras. Quando rumamos para o plano da prática é que os problemas surgem: que referentes devemos considerar? Que ameaças priorizar? Como o referente deve escapar das ameaças? Segurança seria um conceito relativamente simples, porém sua conceptualização e operacionalização são os pontos de controvérsia.

Booth (1991a) igualmente argumenta que as ameaças contemporâneas ao bemestar dos indivíduos e aos interesses dos países não derivam apenas de exércitos de vizinhos, mas sim de colapsos econômicos, opressão política, escassez de alimentos, rivalidades étnicas, dentre outras. Adicione-se o fato de que, muitas vezes, os principais perigos partem dos próprios Estados, entidades que, em tese, ao serem asseguradas, consequentemente proveriam segurança às suas populações. Segurança, portanto, não pode ser entendida como sobrevivência, pois sobrevivência significa meramente continuar a existir e não necessariamente viver bem. Logo, conforme Booth (2007), tal conceito deveria ser compreendido como sobrevivência-e-algo-a-mais (survival-plus), com este algo-a-mais referindo-se a alguma liberdade para se viver uma vida livre de ameaças existenciais e abrindo a possibilidade para escolhas.

Aqui, procede-se o enlace com emancipação. Para Booth (2007, p. 112), “emancipação procura garantir a segurança das pessoas daquelas opressões que as impedem de fazer aquilo que livremente escolheriam fazer, compatível com a liberdade dos outros" " . Não se trata de uma situação final, mas um horizonte, que talvez nunca alcancemos. Ademais, emancipação proporcionaria 3 características para a ação teórica e política. Primeiramente, a ancoragem filosófica para distinguir o verdadeiro do falso, isto é, para verificar quais assertivas devem ser levadas a sério. Segundo, como teoria do progresso - progresso entendido de forma reflexiva como um processo dinâmico e reversível e um resultado não necessariamente inevitável da ação política - emancipação oferece uma avaliação do mundo da

9 No original: "Emancipation seeks the securing of people from those oppressions that stop them carrying out what they would freely choose to do, compatible with the freedom of others". 
política internacional apontando que projetos de transformação são possíveis. Em terceiro lugar, como prática de resistência, emancipação seria um framework para realização de objetivos emancipatórios de curto, médio e longo prazos mediante ações políticas estratégicas alicerçadas com base na crítica imanente. Logo, segurança seria o meio; emancipação, o fim.

Com base nessa exposição, é possível depreender os passos analíticos dados pelo autor. Uma primeira ideia importante para a Escola Galesa seria compreender segurança como conceito derivativo. Em outras palavras, diferentes teorias produzem diferentes conceptualizações sobre o que seria segurança. Ainda que relativamente simples, as implicações dessa afirmação são significativas. Para além de ameaças aos indivíduos, estar seguro ou sentir-se seguro é entendido a partir de teorias políticas sobre nações, soberania, classe, gênero e outros fatos (BOOTH, 2005a). Consequentemente, o cânone realista sobre segurança internacional durante a Guerra Fria seria derivado de visões de mundo calcadas, por exemplo, em conceitos anglo-americanos, estatistas, militarizantes e masculinizantes.

Repensar segurança envolve dois passos analíticos adicionais. O primeiro é o que se convencionou chamar aprofundamento (deepening). Essencialmente, aprofundamento significa explorar as implicações da ideia que as atitudes e comportamentos vis-à-vis segurança são derivados de teorias sobre a natureza da política internacional, nos auxiliando a compreender as disputas subjacentes aos conceitos acadêmicos e às agendas políticas. O segundo movimento analítico é o alargamento (broadening), que envolve expandir a agenda dos estudos de segurança para além do escopo estatista e militar. Convém destacar que o alargamento não é necessariamente um movimento progressista, pois o mesmo pode acontecer a partir de uma lógica tradicional, estatista e militarizante. Alargamento, na perspectiva da Escola Galesa, deve ser pensado para além do viés estatal e derivado do aprofundamento, transformando temas de segurança em questões de teoria política, o que Booth (2005a) designa como politizar segurança (politicizing security).

Alcançamos então duas definições introduzidas por Ken Booth (2007). Para o autor, Estudos Críticos em Segurança Internacional devem ser entendidos como um subcampo acadêmico da disciplina de Relações Internacionais, cuja principal preocupação é a busca de conhecimento crítico sobre segurança. Conhecimento crítico implica entendimentos que escapem das estruturas, processos, ideologias e ortodoxias canônicas, ao mesmo tempo em que reconhece que as conceptualizações sobre segurança derivam de perspectivas políticas/teóricas/históricas. 
Adiante, Booth (2007) acrescenta a definição de Teoria Crítica da Segurança. Segundo o autor, tal teoria é tanto um compromisso teórico quanto uma orientação política comprometida com a construção da segurança mundial. Como comprometimento teórico, seria um arcabouço de ideias derivadas da tradição crítica em Relações Internacionais, especialmente da Escola de Frankfurt. Enquanto orientação política, é informada pelo objetivo de fortalecer a segurança mundial mediante políticas emancipatórias e redes de comunidade em todos os níveis, incluindo uma potencial comunidade abarcando outras comunidades políticas.

Com o intuito de descrever o trabalho do analista teoricamente informado pela Teoria Crítica da Segurança, Booth (2011) lança mão de uma analogia. Segundo o autor, analistas críticos deveriam não apenas "sussurrar na orelha do príncipe" as melhores opções políticas, mas procurar apartar-se o máximo possível da situação contemporânea e segurar um espelho, mostrando então para as pessoas como o mundo é e como continuará a ser caso nosso comportamento continue dominado pelas ideias que nos formaram. Nesse ponto, parece-nos apropriado introduzir a discussão de Wyn Jones $(1995$; 1999) sobre o papel do analista crítico.

Partindo da distinção gramsciana entre intelectual tradicional, aquele que seria capaz de transcender as clivagens sociais e produzir conhecimento universal (ambas situações que Gramsci julgava ser uma quimera), e intelectuais orgânicos, os quais teriam consciência de seu papel como articuladores e organizadores de interesses e aspirações de dada classe (GRAMSCI, 1971), Wyn Jones defende que esse último deveria ser o arquétipo do analista crítico. Dessa forma, a tarefa primordial dos Estudos Críticos em Segurança Internacional é, centrando-se nas experiências de homens, mulheres e comunidades para os quais a ordem mundial é causa de insegurança, e mediante uma crítica imanente, construir um discurso de segurança contra-hegemônico.

Há, em alguma medida, um caráter pedagógico nessa tarefa, dado que ao se criticar o bloco hegemônico, assim como apontando as diferentes concepções de segurança oriundas de diferentes entendimentos das potencialidades humanas, o analista crítico estaria, a um só tempo, contribuindo para a erosão do presente status quo e abrindo espaço para uma posição contra-hegemônica. Todavia, convém apontar que, na prática, a relação do analista com a classe ou movimento social com o qual está alinhado não é simplesmente de instruir e ensinar. Trata-se de um relacionamento reflexivo, em que a teoria alimenta a prática e que essa última também é capaz de reformular a teoria. Ao se proporcionar uma crítica da 
corrente ordem, o analista abre espaços políticos para que classes e movimentos sociais avancem em direção a objetivos emancipatórios.

\section{Prática}

Seguindo a tradição da Teoria Crítica, a Escola Galesa afirma a importância da práxis transformadora, em paralelo com as elaborações teóricas. Logo, tanto Booth (2005a) quanto Wyn Jones (1999) destacam a importância de estudos concretos que possam ampliar nossa compreensão sobre as várias realidades de insegurança existentes no mundo. Com esse aviso em mente, não nos parece menor a tarefa de proporcionarmos vislumbres de como algumas das ideais de todo esse cabedal teórico podem informar análises empíricas. Dessa forma, o objetivo da seção é duplo: ilustrar o potencial analítico da Escola Galesa para os casos selecionados e depreender desses estudos os arcabouços analíticos e metodológicos utilizados, auxiliando aqueles dispostos a utilizar tais ideias. Para tanto, foram selecionados dois exemplos, um mais alinhado a ideias gramscianas, outro de matriz frankfurtiana.

\section{O debate sobre Estados Falidos}

Após os atentados terroristas de 11 de setembro de 2001, houve uma proliferação de estudos acadêmicos sobre os chamados Estados Falidos. Tais trabalhos surgiram como uma tentativa de se entender a situação sociopolítica de países do dito Terceiro Mundo e como tal conjuntura incentivava a proliferação de grupos terroristas. Grosso modo, tal literatura compartilha alguns pressupostos, dos quais dois em particular se destacam.

Primeiramente, o fracasso estatal afloraria a partir da inabilidade das lideranças internas de determinados países em implantar instituições governamentais de natureza liberal, consideradas as mais adequadas para o desenvolvimento. Em segundo lugar, a ausência de tais instituições resultaria em problemas internos que extrapolariam as fronteiras nacionais e teriam potencial para atingir outros países. No caso específico do terrorismo, uma vez que tais países não seriam democráticos e o Estado teria dificuldades em prover bens públicos, a população não teria condições de vocalizar suas demandas, criando condições 
de insatisfação que serviriam de combustível para a proliferação de grupos terroristas (MONTEIRO, 2006).

Trata-se certamente de discussão controversa, a qual gerou significativa polarização acadêmica. À luz do diagnóstico acima sintetizado, autores como Helman e Ratner (1992) e Fukuyama (2005) defenderam a necessidade de se intervir em países considerados fracassados com o intuito de democratizá-los e expandir a ordem liberal pelo globo. Contudo, diversos analistas passaram a questionar o diagnóstico e suas implicações políticas, argumentando que a relação de causalidade entre fracasso estatal e terrorismo empiricamente não se sustenta, da mesma forma que o conceito criaria condições para práticas intervencionistas que estariam mais interessadas em manter o status quo internacional, ao controlarem as regiões entendidas como problemáticas (GOMES, 2011).

Uma interessante crítica a esse conceito é a desenvolvida por Pinar Bilgin e Adam David Morton (2007). De acordo com seus argumentos, há uma preocupação excessiva da literatura tradicional com os supostos sintomas do fracasso estatal, o que prejudicaria o entendimento das condições estruturais que levaram determinados países a tal situação. Nessa toada, Bilgin e Morton denominam tais análises tradicionais de externalistas e reducionistas. Externalistas por não incluírem o impacto que a globalização e o capitalismo contemporâneo tiveram sobre os países, esquivando-se de abordar como os Estados influenciam e são afetados por esses processos. De outro lado, são reducionistas, pois reduzem as ameaças à segurança ao terrorismo transnacional.

Conforme os autores (BILGIN; MORTON, 2002, 2004), a adjetivação de países enquanto falidos teria consequências problemáticas. A primeira é que sucesso e fracasso são analisados a partir de uma avaliação de capacidades coercitivas dos países para controlarem seus territórios, restringindo a discussão sobre a natureza da democracia em tais territórios. Outrossim, a visão da fragilidade estatal como comportamento desviante de normas internacionalmente reconhecidas serviria como justificativa para intervenções. Por fim, negligenciam-se os impactos dos programas de ajuda e estruturação econômica capitaneados por organizações como o Fundo Monetário Internacional e Banco Mundial, que muitas vezes criam e/ou exacerbam os sintomas do fracasso.

Teríamos, portanto, uma vilanização da pobreza, porquanto as análises concentram-se no comportamento político de tais países e nas implicações desse comportamento sobre a segurança da ordem econômica liberal, sem questionar o contexto econômico no qual tais comportamentos estão incluídos. Para além da 
crítica, Bilgin e Morton (2007, p. 21) apresentam uma alternativa analítica para uma discussão:

Uma maior consideração precisa ser dada a como as diferentes lógicas de soberania e capitalismo se combinam e formatam as condições estruturais que confrontam os Estados pós-coloniais - “falidos” ou qualquer outro adjetivo. Essas contradições são capturadas pela maneira como países específicos internalizam processos de acumulação de capital e formas de dominação (...) Em suma, uma historicização mais profunda dos processos de formação estatal no mundo não-ocidental é necessária, ciente das circunstâncias políticas e econômicas nas quais estes Estados evoluíram ${ }^{10}$.

Ainda que não esteja precisado um framework teórico-metodológico nas análises dos autores, é possível depreender conceitos da Escola Galesa nas entrelinhas do argumento, especialmente as cruciais ideias de aprofundamento e alargamento.

Num primeiro momento, ambos autores averiguam a relação entre a academia estadunidense e o mundo político durante e após a Guerra Fria, defendendo a tese de que a primeira foi anexada pelo segundo (BILGIN; MORTON, 2002). Uma das consequências dessa relação seria a representação de países pós-coloniais, sempre vistos a partir das ideias de deficiência e/ou fracasso vis-à-vis o Ocidente, cuja expressão Estado Falido seria o capítulo mais recente. Salvo melhor juízo, visualiza-se o aprofundamento quando os autores mergulham na avaliação das condições de produção do conhecimento sobre o tema e procuram explorar não apenas que ideias informam teoricamente a construção do conceito, mas ponderam sobre suas implicações concretas na prática política.

O alargamento ocorre quando os autores se movem além de uma lógica securitizadora, na qual Estados Falidos são vistos unicamente pelo prisma da segurança internacional, e do contraterrorismo em especial, e defendem que a análise da situação de tais países deveria levar em consideração questões sobre soberania, democracia e capitalismo ou, relembrando a famosa lição de Cox (1981), como a parte se encaixa no todo.

10 No original: "What needs to be given greater consideration is how the different logics of sovereignty and capitalism are intertwined which shape the structural conditions confronting postcolonial states-'failed'or otherwise. These contradictions are captured through the manner in which specific state forms internalize capital accumulation processes and associated forms of rule. (...) In sum, a thorough historicisation of state formation processes in the 'non-Western' world is required that is cognisant of the political economy circumstances within which such states have evolved". 


\section{Peacebuilding e emancipação}

No outono de 1992, preocupado com os conflitos em andamento na Croácia e Bósnia-Herzegovina, pois poderiam trazer consequências para a Macedônia, o presidente Kiro Gligorov solicitou à ONU a presença de tropas no país. Nesse sentido, em 11 de dezembro de 1992, o Conselho de Segurança decidiu adicionar um Comando Macedônico (Macedonian Command - MC) à United Nations Protection Force (UNPROFOR), que já atuava nos países supracitados. A UNPROFOR-MC objetivava monitorar as fronteiras da Macedônia com a Albânia e a então República Federativa da Iugoslávia e fortalecer a segurança e estabilidade do país mediante a presença da missão in loco.

Um ano após o envio das tropas, o diagnóstico dentro da ONU era de que a situação na Macedônia havia piorado, levando a uma expansão do mandato da UNPROFOR-MC. Já em 1995, toda a missão na ex-Iugoslávia foi reorganizada a pedido dos países receptores, culminando na criação da United Nations Preventive Deployment Force (UNPREDEP) para a Macedônia. Contudo, tendo em vista a deterioração da situação no Kosovo em 1998 e o veto chinês contra a extensão do mandato, a UNPREDEP encerrou suas atividades em 28 de fevereiro de 1999.

A presença da ONU na Macedônia é o foco de Eli Stamnes (2005). Sua preocupação é entender se o envio dos capacetes azuis foi um fator positivo para a melhoria da situação do país, centrada não em um viés estadocêntrico, mas sim na ideia de segurança humana, tal como delineada no Human Security Report, de 1994, desenvolvido pelo PNUD. A despeito de problemas organizacionais e logísticos, o resultado da análise apresenta a missão como um agente emancipatório no país, sobretudo pelo fato de que várias atividades desenvolvidas contribuíram para a melhora da vida da população.

Stamnes delineia claramente qual será sua estratégia analítica para a execução da pesquisa e sua grande inovação é a tentativa de operacionalizar a ideia de crítica imanente. Tomando a definição de Booth (2007) como referência, a crítica imanente procura identificar determinadas características em situações concretas (tais como dinâmicas positivas, agentes, entre outras) que possam ter possibilidades emancipatórias e, a partir de então, lutar para fortalecê-las. A autora construiu um enquadramento que procura traduzir analiticamente a meta da crítica imanente e, então, a aplica ao caso da UNPROFOR-MC e da UNPREDEP.

Basicamente, são dois movimentos que Stamnes realiza. O primeiro, denominado desconstrução, consiste na contraposição das concepções de segurança 
que informam o discurso da missão com as ideias de segurança que se expressam na prática. Aqui, o foco é apontar as contradições que potencialmente possam se tornar variáveis para transformações positivas. O segundo passo, reconstrução, é avaliar quais dessas variáveis podem ser de fato contribuições para um processo emancipatório. A avaliação é feita com base nas ideias de Axel Honneth, expoente da terceira geração da Escola de Frankfurt, o que demonstra uma possível segunda contribuição da autora: introduzir no âmbito da Segurança Internacional ideias desse autor.

Brevemente, a proposta de Honneth (2003) é entender as lutas sociais mediante a ideia de reconhecimento. Conforme o autor, indivíduos se formam e constituem suas identidades pessoais a partir do momento em que são reconhecidos intersubjetivamente. Existem três formas principais de reconhecimento que, se deterioradas, teriam potencial para motivar conflitos: amor, direito e solidariedade. Para o autor, mudanças sociais podem ser compreendidas mediante uma dinâmica de desrespeito. Logo, maus tratos e violação, que ameaçam a integridade física e psíquica, seriam uma violação ao primeiro tipo de reconhecimento. A privação de direitos e exclusão que ferem a integridade social do indivíduo como membro de uma comunidade política seriam exemplos de violação ao segundo tipo de reconhecimento. Por fim, um exemplo de violação da solidariedade seria degradação e ofensas, que afetam os sentimentos de honra e dignidade do indivíduo como membro de uma comunidade.

Em sua análise reconstrutiva, Stamnes contrapõe as ações empreendidas pela missão que mais se aproximaram da ideia de reconhecimento. Por isso, a ênfase no monitoramento de eleições, pois essas podem ser interpretadas como reconhecimento daqueles que fazem parte da comunidade política; na forma como organizações da sociedade civil foram reconhecidas como partícipes do processo de paz; e na maneira como a operação contribuiu para melhorar a situação socioeconômica da população, pois ajudou a mitigar formas estruturais de desrespeito à vida humana. A despeito das críticas ao pensamento de Honneth ${ }^{11}$, tem-se aqui uma tentativa de operacionalizar a ideia de crítica imanente, que pode auxiliar pesquisadores interessados em análises críticas sobre operações de paz.

11 Nancy Fraser critica a ideia de reconhecimento com base no fato de que, na forma como está posta a discussão, retira do debate questões de justiça distributiva. Em síntese, o reconhecimento deslocaria para um segundo plano a exploração socioeconômica. Para maiores detalhes, Fraser e Honneth (2003). 


\section{Críticas}

A despeito dos avanços, as contribuições da Escola Galesa não estão isentas de controvérsias. Dentre as principais interrogações, dois conjuntos saltam aos olhos: as que problematizam as insuficiências analíticas de seus conceitos, e aquelas interessadas em discutir as implicações teóricas e políticas do equacionamento entre segurança e emancipação.

Ao prospectarem o futuro dos estudos críticos, especialmente as produções da Escola de Copenhagen e da Escola Galesa, Browning e McDonald (2011) questionam a ausência de discussões em ambas linhagens sobre a política da segurança e a ética da segurança. Sobre o primeiro ponto, a ideia é verificar o interesse dos estudos críticos pelas formas como representações de segurança são capazes de definir identidade de grupos e, por conseguinte, habilitar determinadas políticas e legitimar certos atores como provedores de segurança. Em relação ao segundo ponto, trata-se de verificar como ambos conjuntos teóricos discutem o que seriam práticas consideradas progressistas vis-à-vis segurança, implicando tentativas de definir a natureza e a dinâmica do progresso. No arrazoado realizado, Browning e McDonald argumentam que Copenhagen e Aberystwyth não conseguem proporcionar um arcabouço convincente para a investigação de ambos os pontos.

Aqui é preciso distinguir que críticas cabem a cada escola. Se a política da segurança é um dos focos de maior atenção da Escola de Copenhagen, sobretudo pela centralidade da discussão envolvendo a ideia de securitização, para a Escola Galesa tal discussão não é o ponto principal. Booth (2007) concorda com o fato de que segurança tem grande poder e que enquadrar determinados temas por esse prisma eleva-os a um status de prioridade. Para além, Booth (2007, p. 168) é relativamente crítico à ideia de dessecuritização, pois essa "poderia ser vista como um movimento realizado por elites para retirar a significância das reais inseguranças"12. Trocando em miúdos, Booth considera que a dessecuritização pode desempoderar determinados temas e atores na medida em que tópicos urgentes passariam para um segundo plano do debate. Ademais, outra crítica de Booth direcionada à Escola de Copenhague é a distinção que fazem entre o âmbito da política e o âmbito da segurança, assim como a visão conservadora que possuem do último. A saída, segundo Booth, seria conceber segurança como teoria política.

12 No original: "Desecuritisation could indeed be a move by the powerful to lower the significance of real insecurities". 
Destrinchando a primeira crítica de Browning e McDonald, a contraposição entre as Escolas aponta um binário que perpassa esses estudos críticos. Se, para a Escola de Copenhagen, a securitização teria um efeito deletério, para Booth o efeito da segurança para fins de emancipação seria benigno. Logo, aparentemente independente de tempo e espaço, segurança teria sempre a mesma lógica. O que se perde é o reconhecimento de que segurança tem sim implicações distintas em tempos e espaços diferentes, indo além do que apenas consequências emergenciais ou benignas.

Com relação à ética da segurança, um dos pontos de controvérsia principal deriva da pouca problematização do que seriam práticas progressistas. Browning e McDonald destacam que Booth possui uma concepção fundacionista e materialista de emancipação e segurança, relacionando-a com condições materiais para sobrevivência. Contudo, em seu trabalho mais recente, Booth (2007) também passa a priorizar a dimensão procedural da emancipação, assim como a importância de questões relativas a deliberação. O que os autores apontam é que a relação entre deliberação e condições matérias vis-à-vis emancipação levanta questões complexas - por exemplo, como garantir espaços para deliberação em condições de desigualdades materiais -, mas que são pouco discutidas.

Em adição a esse ponto, ainda que enxergue emancipação de maneira progressiva, Booth, por vezes, restringe-se a repetir princípios éticos liberais, sobretudo em discussões envolvendo intervenções humanitárias. À guisa de exemplificação, o autor esquiva-se de discutir qual o papel da violência e o que seria emancipação em situações de genocídio, optando por apenas endossar a posição de que, se o envio de tropas é necessário, elas devem fazer mais bem do que mal ao contexto em foco. Nesse ponto, explicita-se ainda mais a base liberal da concepção de emancipação de Booth, interessada na defesa de direitos dos indivíduos, o que se choca com sua herança marxista, que pensa emancipação a partir de uma crítica imanente das condições estruturais e materiais e que tem em seu horizonte político o papel da revolução como meio para o progresso. Logo, um dos grandes problemas das insuficiências levantadas é que se torna difícil derivar posicionamentos éticos para ações específicas a partir de afirmações amplas e contraditórias.

Em linha semelhante, Peoples (2011) argumenta que Booth possui uma visão muito circunscrita do que seria emancipação. Isso se deve ao fato de que a Escola de Frankfurt é apenas uma das influências dentro do cabedal teórico do autor e que seu engajamento com ela não seria tão profundo - diferentemente de 
Wyn Jones (1999), cuja meta é traduzir tal tradição para os estudos de segurança. Contudo, discutir emancipação dentro da Escola de Frankfurt também é discutir o papel da violência e da resistência. Herbert Marcuse (apud PEOPLES, 2011), expoente dessa tradição, argumentou que, no limite, aderentes do princípio de não violência estariam perpetuando um sistema no qual a violência é inerente. Independentemente da controvérsia que afirmações como essas criam, autores alinhados à Frankfurt não se esquivaram de enfrentá-las. O mesmo não se poderia dizer sobre a Escola Galesa.

Não obstante a relevância das críticas até o momento arroladas, sem sombra de dúvida os maiores questionamentos são endereçados à relação estabelecida entre segurança e emancipação. Para explorarmos as avenidas de problematização possíveis a essa equação, parece-nos importante retomar novamente as definições de emancipação e crítica imanente.

Conforme descrito acima, "emancipação procura garantir a segurança das pessoas daquelas opressões que as impedem de fazer aquilo que livremente escolheriam fazer, compatível com a liberdade dos outros”13 (BOOTH, 2007, p. 112). Aqui cabem ao menos duas questões: quem é o agente emancipador? Quem é o sujeito a ser emancipado? Sobre crítica imanente, sua tarefa seria revelar determinadas características em situações concretas (tais como dinâmicas positivas, agentes, entre outras) que possam ter possibilidades emancipatórias. A questão que aqui salta aos olhos é revelar para quem. Outrossim, como realizar todas essas tarefas a partir de uma perspectiva de segurança?

Aradau (2004) interroga a proposta galesa a partir desse último questionamento. Quando Booth faz sua famosa proposição, emancipação torna-se problemática, pois engessa-se a possibilidade de transformação social, inserida agora dentro de uma lógica de segurança. Qual seria essa lógica? Em última instância, seria uma lógica ordenadora schmittiana, a qual ancora-se na discriminação entre amigo e inimigo e criação de hierarquias. Contudo, emancipação deveria ir além, informada, ao menos em tese, pela possibilidade de uma reconciliação social entre todos. Por que não, então, discutir emancipação a partir de enquadramentos distintos, eventualmente mais conectada com política democrática e questões de igualdade, justiça e/ou direitos humanos? Não menos importante, discutir emancipação dissociada de questões de produção é insuficiente, o que denota a pouca atenção da Escola Galesa com a dimensão econômica (HERRING, 2007).

13 No original: "Emancipation seeks the securing of people from those oppressions that stop them carrying out what they would freely choose to do, compatible with the freedom of others". 
Na mesma toada, inspirado por insights pós-estruturalistas que criticam a própria ideia de emancipação como uma grande meta narrativa capaz de servir como justificativa para práticas opressoras, Neocleous (2008) dispara a seguinte questão: será que no coração da lógica da segurança repousaria não liberdade e emancipação, mas, sim, um projeto cujo intuito é moldar as sociedades humanas a partir de determinada visão de mundo? Em caso de resposta positiva, Neocleous defende que o outro lado da moeda da segurança não seria emancipação, como Booth disse em 1991, mas, sim, opressão.

As demais questões acima apresentadas são tratadas de forma bastante aguda por Hynek e Chandler (2013). Numa conjuntura pós-Guerra Fria, preenchida por conflitos civis, pobreza e desigualdades, é inquestionável a existência de sujeitos a serem emancipados. Entretanto, quem seria o sujeito emancipador? Esse talvez seja o maior problema enfrentado pela Escola Galesa: uma teoria emancipatória sem um sujeito emancipador contra-hegemônico. A grande contradição embutida nesse conjunto de ideias é, portanto, o fato de que o projeto emancipatório seria conduzido por potências e instituições internacionais encarregadas de garantir (ou mesmo expandir) a ordem liberal. O diagnóstico dos autores é que o boom nos Estudos Críticos durante os últimos 25 anos explorou mais alternativas reformistas dentro da lógica dominante do que proporcionou claridade teórica às forças contra-hegemônicas. Aquém, portanto, de uma crítica imanente.

Quais foram as condições que provocaram tal estado de coisas? Aqui cremos ser interessante colocarmos à prova duas hipóteses. A primeira delas refere-se ao papel do analista e a quem ele revela as condições emancipatórias. Conforme nos diz Wyn Jones (1995), o arquétipo do analista crítico seria o intelectual orgânico gramsciano, que contribuiria para o processo de criação de consciência de si e para si de determinada classe. Todavia, como se comportar na relativa ausência de movimentos críticos? Frente a tal questão, Wyn Jones nos recorda dos movimentos pacifistas dos anos de 1980 que se beneficiaram do amontoado de ideias desenvolvidas nos anos 1960 e 1970 e aponta para o fato de que, nesses casos, o arquétipo de intelectual poderia ser de inspiração adorniana.

Após a publicação de Dialética do Esclarecimento, Adorno encontrava-se descrente sobre a capacidade do intelectual em influenciar a prática política. Dentro de uma conjuntura em que a razão instrumental havia dominado a sociedade capitalista, bloqueando as possibilidades de emancipação, Adorno via sua filosofia como "mensagens que deveriam ser lançadas no mar da 
história"14, com a esperança de que alguém no futuro as coletasse (apud WYN JONES, 1995, p. 307). Inspirado pelo exemplo dos movimentos pacifistas supracitados, Wyn Jones antecipava ser esse o caminho do analista crítico vis-à-vis a ausência de movimentos críticos.

Essa é a primeira hipótese que cremos ser interessante apresentar. Analistas críticos lançaram ideias e conceitos ao mar da história durante os últimos 25 anos, com a esperança de que, em algum momento, alguém as recolhesse e informasse sua prática política. Em parte, concordamos com Hynek e Chandler (2013), quando afirmam que ideias podem até terem sido criadas, mas clareza intelectual para forças contra-hegemônicas não foi desenvolvida. Nosso ponto de discordância localiza-se no motivo de tal tarefa não ser realizada. Aparentemente, Hynek e Chandler defendem o argumento de que esse resultado se deve à ênfase em advocacy ao invés de crítica por parte dos analistas críticos. Uma explicação complementar, e a segunda hipótese que apresentamos, é a de que houve um processo de gentrificação de parte das ideias desenvolvidas no bojo do movimento crítico.

O que seria esta gentrificação? Aqui, seguimos o insight de Cynthia Weber (2014). Gentrificação seria uma expressão cunhada para descrever o fluxo da população de classe média para outros bairros, removendo as pessoas mais carentes da região. Tal remoção não se restringe a prédios e moradias, mas também a ideias. Gentrificação implica, portanto, substituição, homogeneização e assimilação. A analogia proposta seria a seguinte.

Weber (2014) argumenta que os bairros mais carentes de Relações Internacionais, povoados pelos imigrantes intelectuais marxistas, pós-estruturalistas, feministas, teóricos críticos, pós-coloniais, dentre outros, estariam produzindo insights teóricos para uma disciplina que passava por uma crise intelectual no pós-Guerra Fria. Logo, o mainstream passou a ocupar partes dessa região, reconhecendo que ideias ali produzidas poderiam reavivar a disciplina. Contudo, os custos do contato foram grandes, com a incorporação de um vocabulário mais palatável para o grande público. Em suma, uma economia política internacional mais geral foi oferecida em substituição ao marxismo; a variável gênero substituiu o feminismo; construtivismo por pós-estruturalismo; entre outras consequências. Logo, não nos parece descabido afirmar que ideias produzidas no bojo do campo crítico em Segurança Internacional parecem ter sofrido processos de gentrificação. Duas delas prestam-se como exemplos.

14 No original: "Message in a bottle to be cast on the waters of history". 
A primeira é a própria ideia de Segurança Humana, que emerge a partir da discussão sobre novos referentes para além do Estado. Além das controvérsias envolvendo as diferentes concepções de Segurança Humana defendidas pelo PNUD e por potências médias como o Canadá, assim como as críticas que destacam sua ambiguidade (PARIS, 2001), o debate em torno do conceito reduziu-se a uma discussão em torno de um indivíduo genérico ou a humanidade como um todo, o que culmina em uma marginalização de questões importantes, como as de gênero, por exemplo (CHENOY, 2005; WALKER, 2006). A dimensão privilegiada do debate seria, então, aquela que se adequa mais a uma visão liberal sobre segurança, hoje hegemônica especialmente na literatura sobre peacebuilding. ${ }^{15}$

A segunda é a discussão envolvendo a ideia de ownership local em situações pós-conflito. A literatura crítica sobre peacebuilding argumenta que um dos motivos do fracasso do modelo liberal de construção da paz seria oriundo da natureza top-down do processo de intervenção e do pouco engajamento com a população e práticas locais. Consequentemente, houve um esforço em passar a condução dos processos de construção da paz para atores locais. Ainda que hoje seja comum encontrarmos em documentos da ONU a defesa do ownership local, para além da crítica de que esse seria um mero movimento retórico, muitas vezes sua operacionalização padece de problemas. A crítica mais frequente seria que o ownership local estaria embebido num framework liberal no qual o processo, de fato, seria reduzido à aplicação, pelos locais, de normas externas acordadas alhures e com pouca aderência ao país no qual serão implementadas (MAC GINTY, 2011).

Não restam dúvidas de que, em termos teóricos, a discussão crava interrogações importantes na produção da Escola Galesa e de outras linhagens críticas. Todavia, no âmbito da prática da segurança internacional, essa discussão tem ressonâncias igualmente problemáticas. Mais de um quarto de século de tentativas de experimentação conceitual e ações políticas podem até ter melhorado a vida de parte da população mundial, entretanto, conflitos civis ainda afetam a vida de muitos $^{16}$, sem mencionar suas externalidades, como a recente crise de refugiados europeia demonstra ${ }^{17}$. Assim, se as atuais alternativas emancipatórias vêm

\footnotetext{
15 A literatura sobre peacebuilding discute, dentre outros pontos, a estabilização de países saídos de conflitos. Há uma diversa gama de analistas que povoam tal discussão, desde liberais até marxistas, pós-estruturalistas e pós-colonialistas. Para uma introdução, ver Mac Ginty (2013).

16 À guisa de ilustração, apenas na Síria, em abril de 2016, a ONU estimava em 400.000 o número de mortos no conflito. (ALJAZEERA, 2016)

17 “Mais de 146 mil refugiados e migrantes chegaram à Europa em 2016”. (DIÁRIO DE NOTÍCIAS, 2016).
} 
fracassando e enfrentando resistências para serem implementadas ${ }^{18}$, parece-nos que uma pergunta pertinente a ser enfrentada poderia ser formulada nos seguintes termos: como atrair para os ditos processos emancipatórios os sujeitos a serem emancipados?

\section{Conclusões}

Tendo como pano de fundo a última interrogação lançada, cabe-nos ao fim explorar que eventuais respostas teóricas e políticas temos para a referida pergunta. Salvo melhor juízo, três merecem destaque.

A primeira é do próprio Ken Booth (2007). Ciente das complexidades teóricas embutidas no conceito, assim como da possibilidade de movimentos retóricos fazerem uso da emancipação meramente para justificar práticas políticas, o autor apresenta uma distinção entre o que seriam emancipações verdadeiras de emancipações falsas. Em linhas gerais, dentre as principais características de uma dita falsa emancipação, Booth (2007) destaca concepções que sejam estáticas e atemporais, que defendam políticas emancipatórias que produzam custos em terceiros ou utilizem emancipação como rótulo para acobertar o poder do Ocidente ou de qualquer outra entidade. Trata-se, então, de distinguir emancipações autênticas de falsas, mediante análise de circunstâncias históricas concretas.

Todavia, quem distingue e quem está sendo distinguido, ainda que sejam perguntas que só possam ser respondidas à luz da empiria, remetem a problemas relativos a quem emancipa, em relação a que se emancipa e quem seria o emancipado. Como visto nas críticas, tais questionamentos, por vezes, reduzem-se a julgamentos de valores, algo de difícil resolução, tanto no registro teórico, porém, especialmente, no âmbito político.

Uma segunda resposta vem a partir da experiência do que está convencionando-se chamar Escola de Manchester, anteriormente baseada em Saint Andrews, Escócia, e ancorada particularmente nos trabalhos de Oliver Richmond e Roger Mac Ginty. Sumariamente, ambos autores defendem o argumento de que a intervenção de atores externos com objetivos emancipatórios deve ser resultado da interação com atores locais, culminando em formas híbridas ou pós-liberais de paz e segurança (MAC GINTY, 2011; RICHMOND, 2011). Nessa perspectiva, a

18 Para o contexto de operações de paz, ver a coletânea organizada por Richmond e Franks (2009), na qual, mediante um conjunto de estudos de casos, os autores apontam as resistências que as missões da ONU enfrentam. 
resposta para a lacuna de legitimidade expressa pela pergunta que encerra a seção anterior jaz no reconhecimento da diversidade cultural e no aprofundamento das potencialidades da teoria pós-colonial. A principal consequência dessa abordagem seria diminuir os horizontes do que seriam práticas emancipatórias, sem possibilidade de universalização para outros contextos.

Por fim, uma terceira resposta depreende-se de discussões relativas ao alcance da emancipação. Aradau (2004) sugere um diálogo maior com as tradições pós-estruturalista e pós-marxista e a forma como um conjunto determinado de autores discute o dilema entre universalidade e diferença.

Em nosso entendimento, trata-se de alternativa relevante, porém que depende de um diálogo sem preconceitos e que supere afirmações simplistas como a de que “a rejeição pós-modernista de metanarrativas e de solidariedades universais não produz opções políticas para pessoas em perigo"19 (BOOTH, 2005c, p. 270). Para uma melhor compreensão de tais propostas, aqui há de se distinguir entre o plano ontológico e o plano ôntico. No plano ontológico, tradições pós-estruturalistas criticam as ditas metanarrativas com base no fato de que essas se prestam para construir posições de autoridade para decisões contingentes, tomadas em terreno indecidível, no qual outras opções poderiam ter sido autorizadas. Logo, não haveria nada essencialmente universal que transcendesse a história e que fosse tarefa teórica desvelar sua lógica e tarefa política concretizá-la (LACLAU, 2011). Pelo contrário: o máximo que podemos afirmar é que a história seria uma guerra de trincheiras, com projetos políticos distintos lutando para preenchê-la.

No plano ôntico, contudo, permitem-se diversas possibilidades políticas a partir de tais implicações ontológicas. Se não há lógica transcendental e tampouco um agente privilegiado de mudança histórica, o universal nada mais seria do que um particular que, em algum momento, se tornou dominante, o que, politicamente, abre espaço para a articulação de diversas lutas possíveis. Todavia, essas são constituídas a partir de antagonismos sociais: constroem-se mediante a contraposição com uma ordem que, ao mesmo tempo em que as impede de alcançarem suas demandas, são a condição para a própria articulação da luta política (LACLAU, 2011). Por exemplo, a um só tempo o patriarcalismo impediria a concretização dos ideais feministas, mas seria também condição de possibilidade para a formação de uma identidade política feminista. Logo, pluralizam-se as lutas políticas e multiplicam-se as possibilidades ditas emancipatórias. Ainda

19 No original: "The postmodern rejection of metanarratives and universal solidarities does not deliver a helpful politics to people in trouble”. 
que onticamente, por vezes, determinado projeto possa parecer a solução final, ontologicamente terá sempre um caráter contingente e precário, cuja sustentação depende do arranjo de forças de dado momento histórico, podendo posteriormente ser substituído por alternativa igualmente considerada emancipatória.

As duas últimas propostas discutidas permitem repensar o nexo entre segurança e emancipação, porém em registro distinto. Deve-se abandonar a ideia de uma sociedade finalmente reconciliada consigo mesma e isenta de conflitos. Essa sempre será heterogênea e preenchida por antagonismos sociais. Logo, a definição do que seria segurança igualmente depende de cortes antagônicos que, em última instância, vão definir quem são os agentes que proporcionam segurança, assim como aqueles que devem ser assegurados. Para além, onticamente, uma proposta de segurança pode eventualmente ser vista como a única possível, porém, ontologicamente, ela seria um projeto particular que em determinado momento histórico conseguiu hegemonizar dada conjuntura.

Da mesma forma, práticas emancipatórias seriam circunscritas localmente e marcadas por diversidades culturais. Dito de outra forma, definições sobre o que é o político, o econômico, segurança e emancipação devem ser compreendidas como historicamente inseridas em instituições, práticas cotidianas e sociedades, e não como entidades abstratas compreendidas de forma apriorística. Logo, recorrendo à Homi Bhabha (2010), se o hibridismo é possível não porque culturas possuem conteúdo similar, mas, sim, pelo fato de que são práticas interpelativas formadoras de símbolos e subjetividades, o que acaba abrindo novos espaços para articulação política, não nos parece descabido tentar compreender emancipação em termos semelhantes, como articuladora de propostas materiais, simbólicas e de subjetividades a partir de determinada conjuntura sócio-histórica.

Feitas as contas, lançamos a seguinte provocação: ao invés de segurança e emancipação, teríamos seguranças e emancipações.

\section{Referências}

ALJAZEERA. Syria death toll: UN envoy estimates 400,000 killed: Staffan de Mistura's estimate, which far exceeds those given by UN in the past, is not an official number. 13 ar. 2016. Disponível em: < http://www.aljazeera.com/news/2016/04/staffan-demistura-400000-killed-syria-civil-war-160423055735629.html > . Acesso em: 10 jul. 2016. ARADAU, Claudia. Security and the Democratic Scene: Desecuritization and Emancipation. Journal of International Relations and Development, 7, 2004, p. 388-413. 
AZEVEDO, Thalia. A Escola Galesa de Estudos Críticos em Segurança: Segurança como Emancipação. Dissertação de Mestrado. São Paulo: Programa de Pós-Graduação em Relações Internacionais Santiago Dantas (UNESP/UNICAMP/PUC-SP), 2009.

BHABHA, Homi. The third space (interview with Homi Bhabha). In: RUTHERFORD, Jonathan (ed.) Identity, Community, Culture, Difference. London: Lawrence \& Wishart, 1990, cap. 10, p. 207-221.

BILGIN, Pinar; MORTON, Adam. From 'Rogue' to 'Failed' State?: the Fallacy of Short-termism. Politics, vol. 24, n. 3, 2004, p. 169-180.

BILGIN, Pinar; MORTON, Adam. Historicising Representations of 'Failed States': beyond the Cold-War Annexation of the Social Sciences?. Third World Quarterly, vol. 32, n. 1, 2002, p. 55-80.

BILGIN, Pinar; MORTON, Adam. Rethinking State Failure: the Political Economy of Security. In: LAMBACH, Daniel; DEBIEL, Tobias (org.) State Failure Revisited I: Globalization of Security and Neighborhood Effects. INEF REPORT 87, 2007, Cap. 1, p. 7-31.

BILGIN, Pinar. The Continuing Appeal of Critical Security Studies. In: BRINCAT, Shannon; LIMA, Laura; NUNES, João (eds.). Critical Theory in International Relations and Security Studies: Interviews and Reflections. London: Routledge, 2011, Cap. 11, p. 159-171.

BOOTH, Ken. Beyond Critical Security Studies. In: BOOTH, Ken (ed.). Critical Security Studies and World Politics. Boulder: Lynne Rienner Publishers, 2005c, Cap. 11, p. 259-278.

BOOTH, Ken. Challenging the ideas that made us. In: BRINCAT, Shannon; LIMA, Laura; NUNES, João (eds.). Critical Theory in International Relations and Security Studies: Interviews and Reflections. London: Routledge, 2011, Cap. 3, p. 59-81.

BOоTH, Ken. Critical Explorations. In: BOOTH, Ken (ed.). Critical Security Studies and World Politics. Boulder: Lynne Rienner Publishers, 2005a, Introdução, p. 1-18.

BOOTH, Ken. Introduction to Part I. In: BOOTH, Ken (ed.) Critical Security Studies and World Politics. Boulder: Lynne Rienner Publishers, 2005b, p. 21-25.

BOOTH, Ken. Security and Emancipation. Review of International Studies, 17, 1991a, p. 313-326.

BOOTH, Ken. Security in Anarchy: Utopian Realism in Theory and Practice. International Affairs, vol. 67, n. 3, 1991b, p. 527-545.

BOOTH, Ken. Strategy and Ethnocentrism. London: Routledge, 1979.

BOOTH, Ken. Theory of World Security. Cambridge: Cambridge University Press, 2007. BROWNING, Christopher; MCDONALD, Matt. The Future of Critical Security Studies:

Ethics and the Politics of Security. European Journal of International Relations, vol. 19, n. 2, 2011, p. 235-255. 
BUZAN, Barry; HANSEN, Lene. A Evolução dos Estudos de Segurança Internacional. São Paulo: Editora UNESP, 2012.

CHENOY, Anuradha. A Plea for Engendering Human Security. International Studies, 42, 2005, p. 167-179.

COX, Robert. Social forces, states and world orders: beyond International Relations theory. Millennium, vol. 10, n. 2, 1981, p. 126-155.

DIÁRIO DE NOTÍCIAS. Mais de 146 mil refugiados e migrantes chegaram à Europa em 2016. 11 mar. 2016. Disponível em: < http://www.dn.pt/mundo/interior/maisde-146-mil-refugiados-e-migrantes-chegaram-a-europa-em-2016-5072412.html > . Acesso em: 10 jul. 2016.

FRASER, Nancy; HONNETH, Axel. Redistribution or Recognition? London: Verso, 2003. FUKUYAMA, Francis. Construção de Estados. Rio de Janeiro: Rocco, 2005.

GALTUNG, Johan. Violence, Peace, and Peace Research. Journal of Peace Research, vol. 6, n. 3, 1969, p. 167-191.

GEORGE, Jim. Discourses of Global Politics: a Critical Introduction to International Relations. Boulder: Lynne Rienner Publishers, 1994.

GOMES, Aureo. Questionando o Fracasso Estatal: um Balanço da Literatura Crítica. BIB, 1, 2011, p. 69-94.

GRAMSCI, Antonio. Selections from the Prison Notebooks. New York: International Publishers, 1971.

HELMAN, Gerald; RATNER, Steven. Saving Failed States. Foreign Policy, 89, 1992, p. 3-18. HERRING, Eric. Historical Materialism. In: COLLINS, Allan (ed.). Contemporary Security Studies. Oxford: Oxford University Press, 2007, Cap. 4, p. 42-53.

HONNETH, Axel. Luta por Reconhecimento: a Gramática Moral dos Conflitos Sociais. São Paulo: Editora 34, 2003.

HYNEK, Nik; CHANDLER, David. No Emancipatory Alternative, no Critical Security Studies. Critical Studies on Security, vol. 1, n.1, 2013, p. 46-63.

KRAUSE, Keith; WILLIAMS, Michael. From strategy to Security: Foundations of Critical Security Studies. In: KRAUSE, Keith; WILLIAMS, Michael (eds.). Critical Security Studies: Concepts and Cases. Minneapolis: University of Minnesota Press, 1997, Cap. 2, p. 33-58.

LACLAU, Ernesto. Emancipação e Diferença. Rio de Janeiro: EDUERJ, 2011.

MAC GINTY, Roger (ed.). Routledge Handbook of Peacebuilding. London: Routledge, 2013. MAC GINTY, Roger. International Peacebuilding and Local Resistance: Hybrid Forms of Peace. New York: Palgrave, 2011.

MONTEIRO, Leandro. O conceito de Estado Fracassado nas Relações Internacionais: origens, definições e implicações teóricas. Dissertação (Mestrado em Relações Internacionais). São Paulo: Programa San Tiago Dantas UNESP/UNICAMP/PUC-SP, 2006. 
MUTIMER, David. Critical Security Studies: a Schismatic History. In: COLLINS, Allan (ed.). Contemporary Security Studies. Oxford: Oxford University Press, 2007, Cap. 6, p. 67-86.

NEOCLEOUS, Mark. Critique of Security. Edinburgh: Edinburgh University Press, 2008.

NOBRE, Marcos. A Teoria Crítica. São Paulo: Jorge Zahar, 2004.

PARIS, Roland. Human Security: Paradigm Shift or Hot Air? International Security, vol. 26, n. 2, 2001, p. 87-102.

PEOPLES, Columba. Security after Emancipation? Critical Theory, Violence and Resistance. Review of International Studies, 37, 2011, p. 1113-1135.

RICHMOND, Oliver; FRANKS, Jason. Liberal Peace Transitions: between Statebuilding and Peacebuilding. Edinburgh: Edinburgh University Press, 2009.

RICHMOND, Oliver. A Post-Liberal Peace. New York: Routledge, 2011.

STAMNES, Eli. Critical Security Studies and the United Nations Preventive Deployment in Macedonia. In BELLAMY, Alex; WILliAMS, Paul (eds.) Peace Operations and Global Order. London: Routledge, 2005, Cap. 8, p. 161-181.

WAEVER, Ole. Aberystwyth, Paris, Copenhagen: new schools in security theory and their origins between core and periphery. In: $46^{\circ}$ International Studies Association Annual Conference, 2004, Montreal. Disponível em: http://citation.allacademic.com/ meta/p_mla_apa_research_citation/0/7/4/4/6/pages74461/p74461-1.php. Acesso em: 27 fev. 2017.

WALKER, Rob. The Double Outsides of the Modern International. Ephemera, vol. 6, n. 1, 2006, p. 56-69.

WALT, Stephen. The Renaissance of Security Studies. International Studies Quarterly, vol. 35, n. 2, 1991, p. 211-239.

WEBER, Cynthia. Why is there no Queer International Theory? European Journal of International Relations, vol. 21, n. 1, 2014, p. 27-51.

WYN JONES, Richard. 'Message in a bottle'? Theory and Praxis in Critical Security Studies. Contemporary Security Policy, vol. 16, n. 3, 1995, p. 299-319.

WYN JONES, Richard. On Emancipation: necessity, capacity and concrete utopias. In BOOTH, Ken (ed.). Critical Security Studies and World Politics. Boulder: Lynne Rienner Publishers, 2005, cap. 09, p. 215-235.

WYN JONES, Richard. Security, Strategy and Critical Theory. Boulder: Lynne Rienner, 1999. 